\title{
THREE-DIMENSIONAL MAPS FOR DISASTER MANAGEMENT
}

\author{
T. Bandrova ${ }^{\text {a }}$, S. Zlatanova ${ }^{\mathrm{b}}$, M. Konecny ${ }^{\mathrm{c}}$ \\ ${ }^{\text {a } U n i v e r s i t y ~ o f ~ A r c h i t e c t u r e, ~ C i v i l ~ E n g i n e e r i n g ~ a n d ~ G e o d e s y, ~ S o f i a, ~ B u l g a r i a ; ~ E-m a i l: ~ t b a n d r o v a @ a b v . b g ~}$ \\ ${ }^{\mathrm{b}}$ GIS Technology, OTB Research Institute for the Built Environment, Delft University of Technology, Delft, The \\ Netherlands; E-mail: s.zlatanova@tudelft.nl \\ ${ }^{\mathrm{c}}$ Laboratory on Geoinformatics and Cartography, Institute of Geography, Masaryk University, BRNO, Czech Republic; \\ E-mail: konecny@geogr.muni.cz
}

ICA, ISPRS Commission IV, WG IV/8

\section{KEY WORDS: three-dimensional cartography, map standards, crisis management, user-oriented, value-added}

\begin{abstract}
:
Geo-information techniques have proven their usefulness for the purposes of early warning and emergency response. These techniques enable us to generate extensive geo-information to make informed decisions in response to natural disasters that lead to better protection of citizens, reduce damage to property, improve the monitoring of these disasters, and facilitate estimates of the damages and losses resulting from them. The maintenance and accessibility of spatial information has improved enormously with the development of spatial data infrastructures (SDIs), especially with second-generation SDIs, in which the original product-based SDI was improved to a process-based SDI. Through the use of SDIs, geo-information is made available to local, national and international organisations in regions affected by natural disasters as well as to volunteers serving in these areas. Volunteer-based systems for information collection (e.g., Ushahidi) have been created worldwide. However, the use of 3D maps is still limited.

This paper discusses the applicability of 3D geo-information to disaster management. We discuss some important aspects of maps for disaster management, such as user-centred maps, the necessary components for 3D maps, symbols, and colour schemas. In addition, digital representations are evaluated with respect to their visual controls, i.e., their usefulness for the navigation and exploration of the information. Our recommendations are based on responses from a variety of users of these technologies, including children, geospecialists and disaster managers from different countries.
\end{abstract}

\section{INTRODUCTION}

Disaster management requires the involvement of a variety of people, all of whom have their own professional or personal way of perceiving information. Users do not expect unstructured data, but rather, the representation of these data in an understandable form. Three-dimensional mapping of natural risks and disasters is an area of study that has seen significant growth in the last few years. Virtual environments such as Google Earth, Virtual Earth and Second Life have contributed to the wider acceptance of the third dimension in many fields. These new approaches to visualisation offer new opportunities for disaster managers, enabling users to obtain a clearer perception of the characteristics of disasters, including providing details on the magnitude of an event and improving estimates of evacuation conditions. However, 3D visualisation also brings new challenges.

Generally, the visualisation of information depends not only on the type of data but also on the type of user, including his or her gender, age, disability, behaviour, preferences, habits, task responsibilities, and other characteristics. Many current products (e.g., maps, images, web sites, and 3D environments) for crisis management borrow colour schema, symbols, and map content from existing, application-oriented software, systems, models, and visualisations. These visualisations are not adapted to the specifics of disaster management and fail to consider the context of the user or the decision-making process at the management level in a state of emergency (Fan and Zlatanova, 2008, Snoeren et al., 2006). These aspects have an even larger impact when $3 \mathrm{D}$ environments are considered.
Together with other geo-sciences, cartography has initiated research on new types of maps. Ubiquitous mapping with the ability to map everywhere and for everyone to be involved are only few of the directions for research. In some countries, there has been significant development in the fields of mobile and adaptive cartography, which is also based on 3D mapping.

This paper elaborates on the components of 3D mapping that must be extended and adapted for the purpose of risk and disaster management. The following section discusses 3D maps and their advantages for disaster management. Section 3 illustrates the importance of user-oriented cartography. Section 4 briefly presents the results of several investigations based on user experiences. Section 5 discusses map components and the new requirements for 3D maps. Section 6 summarises the need for international research towards map standardisation.

\section{BENEFITS OF 3D MAPS FOR DISASTER MANAGEMENT}

The first question to be asked in the course of crisis management is 'WHERE?' Where is the disaster? Where are the rescue units? Where are the sources of danger? Where should those in danger be relocated? Without realising it, people often give a reply that has a $3 \mathrm{D}$ component, e.g., 'The fire is on the $6^{\text {th }}$ floor', 'The rescue units are still down in the valley', 'The dam up the hill is in critical condition.' It would be much more illustrative if these answers could be accompanied by 3D maps. However, processing, analysing, and presenting 3D information to emergency responders requires much more attention as compared with the transmission of $2 \mathrm{D}$ data. 
Research on integration of data is progressing. Spatial data infrastructures (SDI) are developing very quickly (Charvat et al., 2008). INSPIRE and GMES support many initiatives for the exchange of data in early warning (EW) and crisis management $(\mathrm{CM})$ in Europe. In Australia, an elaborated approach based on the $2^{\text {nd }}$ generation of SDIs is being adopted (Rajabifard, 2007). These progressive steps are still far short of an ideal situation, but they create a data and information media with guaranteed standards. There are also more and more successful attempts to link SDI data with vital data collected via sensors in real time.

In addition, efforts involving volunteer geographic information (VGI) are becoming increasingly important. Much information is collected and processed by volunteers during disasters. This information poses new challenges, such as how to combine structured (SDI) and non-structured (VGI) data in processes such as disaster management (Goodchild and Glennon, 2010). However, all of these initiatives are only 2D; the 3D component is still progressing. Unfortunately, there is no standard approach for the preparation of 2D/3D maps. Efforts are focused mostly on the content of the data and not on the presentation.

Presently, the use of 3D maps in crisis management is limited. Members of crisis management and integrated rescue forces include a variety of institutions, such as fire services; rescue services (ambulance); police; ministries of environment, industry and trade, transportation, defence; state offices for nuclear safety; local authorities; and other organisations. For many (often historic) reasons, these institutions are equipped with a set of $2 \mathrm{D}$ reference databases (ZABAGED, DMU25, Geobase, ArcCR500, DMR2, UIR-ADR, and analogue maps). Moreover, these organisations construct their own thematic databases according to their own internal needs; for example, databases of settlements and sources of hazards, maps of flood areas and land-use, and orthophotos of selected areas. A variety of software packages maintain the datasets in use. In many cases, a vendor-based (ESRI, Bentley Systems, Intergraph, MapInfo) platform is used, which is supplemented with application software developed specifically for that institution.

3D visualisation and 3D analysis of data are increasingly included in these applications. However, the use of these platforms results in a large variety of vendor-specific symbols, colour schema, and layouts, which creates problems when the 3D models are shared between institutions. From a cartographic point of view, these $3 \mathrm{D}$ visualisations do not comply with cartographic requirements for the use of symbols, legends, and colour compositions. Some examples are shown in Figure 1.

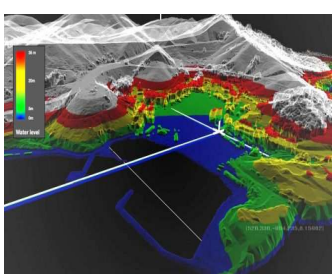

a)

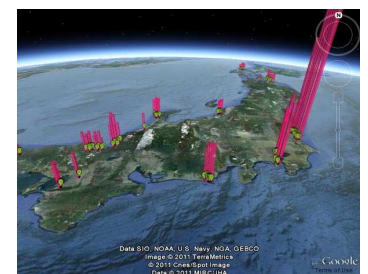

b)
Figure 1: 3D maps of natural disasters: a) 3D map (Barrie, 2011), b) radiation map (Durden, 2011)

The designers have used different 3D point and area symbols. The colour systems are also different. The users are given map legends (Figure 1a), but if they were to use the same presentation to visualise these phenomena on a mobile device, it would be very difficult to direct the user's attention to the legend. In other words, these maps are created according to the author's vision and without any common rules, standards or scientific considerations.

The discussion above clearly shows the need for standards in cartographic visualisation for the purpose of risk and disaster management. These standards could be adapted at the national level, but they must be internationally developed and recognised to enable information sharing in cross-border disasters.

\section{USER-ORIENTED MAPS}

Generally, the purpose of a given map is highly specialised and is related to the characteristics of the user. Traditionally, maps are created with the purpose of specific application or activity for example, a tourist map would change its appearance when it is intended for bicycle trip or a hiking tour or to provide attractive views. Today users need even more specific information and we have able to provide it - we can consider her/his background, the specific tasks she/he needs to perform and also her/his individual tastes and preferences. (Konecny et al., 2011a). The purpose of the map is changing from application-oriented to user-oriented.

Crisis management is an example of a complex process involving different types of users that demands a clear understanding of the user context to be able to produce useroriented maps. In addition, the information to be included in the maps for crisis management depends on the phase of disaster management, the type of disaster, and the type of visualisation (dynamic vs. static).

\subsection{Context}

3D maps pose new challenges to cartographers, and cartographers should work towards providing appropriate map components for crisis management. The 3D presentations should be very well adapted to the context of the user to provide understandable and easy-to-perceive information and messages. This adaptation will speed up the decision-making process and help to minimise damage and protect human lives (Kozel and Stampach, 2010).

In a certain sense, adaptability to the context (of the user or the application) is a kind of cartographic generalisation. In adaptable cartography, the variability of $3 \mathrm{D}$ displays and the variability in the equipment used to display them must be taken into account. Of importance in $3 \mathrm{D}$ representations is the manner in which space is represented considering the level of detail (LOD). The LOD also reflects the necessary amount of information required to make a decision.

In EW and CM, the aim is to adjust the map to the user's cognitive abilities and shorten the time necessary to extract required information from the map.

In addition to the specialisation of existing 3D contexts, new contexts related to specific environments should be created. These adaptations include the hardware characteristics of the visualisation environment (e.g., screen resolution), which influences the size of symbols, the number of distinguishable colours, and transmission characteristics indicating the amount of available data at a given time. They must also take into account the external environment - the time, the season of the year, the location of the user, visibility, and many other 
environmental characteristics. Examples of changes in visualisation according to changes of context are given in Figure 2.

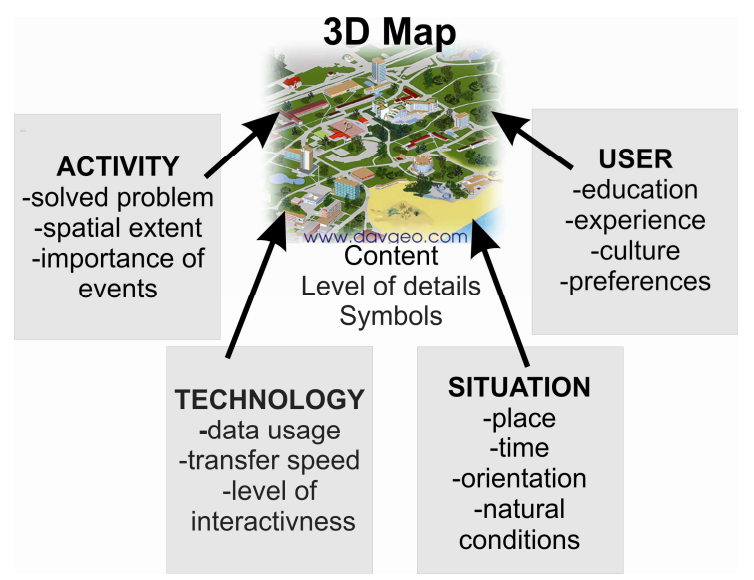

Figure 2: Examples of changes in visualisation according to the change of context (adapted from Stanek et al., 2007)

All combinations of the aforementioned contexts create a large number of potential types of 3D cartographic visualisations. In real-life situations, processing such information is limited by time. To be able to generate a variable content of maps in real time, we have to limit the number of alternatives while preserving all substantial advantages of adaptive cartography. The method for the required selection of alternatives is the definition of generic user profiles, together with a determination of individually adjustable parameters. Similarly, it is possible to determine several typical situations related to map content; such content can be appropriately filtered depending on individual situations.

To create profiles and situational diagrams, it is necessary to analyse the decision-making processes for which the 3D maps are used - what the situations are like, what the roles of users are, and what types of users are likely to take part in responding to the situation. The dependence between a user profile and the situational diagram is apparent when a certain type of user can only face a specific, determined situation.

\subsection{The disaster management phase}

The existing phase of a disaster or risk management process is one of the major factors to consider in developing 3D representations (Konecny et al, 2011b and Reznik et al., 2011). For example, a map to be used for immediate emergency response will differ from a map intended for aftermath or risk assessment. Processes, objects of interest, and tasks should be classified for each phase in disaster management (Zlatanova, 2010). However, many authors agree that the data needed to assess risk and disaster are complementary and must be available to a user at all times (e.g., Neuvel and Zlatanova, 2006).

\subsection{Types of disasters}

The type of disaster primarily influences the objects to be modelled and their representation. The most common disaster subclasses are natural (e.g., floods, landslides, earthquakes, tsunamis, and volcanoes) and human-caused (e.g., industrial accidents, fires, and terrorist attacks). However, definitions and categorisation of disasters vary according to geo-sectors, the geographical and social settings in which they are located. Stingfield (1996) distinguishes between primary (fires, power outages, terrorism, chemical releases, earthquakes, floods, and hurricanes), and secondary disasters (e.g., an earthquake could cause a structural fire, which may, in turn, burn out circuits, resulting in a power failure). Parasuraman and Unnikrishnan (2004) classified natural disasters into two categories: major (earthquake, flood, drought, cyclone) and minor (heat wave, cold wave, landslide, avalanche, tornado). International organisations such as the UN and World Bank have also provided classifications of disaster that can be considered in the development of maps. It is difficult to consider only one type of disaster. For example, floods often trigger landslides; a power failure may result in an explosion and damage to a dam, which can lead to a flood disaster. Therefore, multiple risks and hazards must always be considered (Bell and Glide, 2004).

\subsection{Dynamic vs. static representations}

Natural risks and disasters can be presented on 3D maps using different kinds of visualisation depending on whether static or dynamic information is needed. These risks and disasters can be represented on 3D maps at different scales, with varying LOD, and representing different areas (from world to city and its districts). Computer graphic components such as lights, colours and textures, billboards, fogs, collision detection can be used to enhance the user perception.

Another important aspect of visualisation is virtual camera. The virtual camera can be seen as a new cartographical element of a 3D map, and it is used for the purpose of animation. When the animation parameters are set (focal length, camera angle), the maps designer must take into account the length of the path, the camera speed, and the number of frames per second, to be able to produce an animation of a good quality.

\section{THE COMPONENTS OF 3D MAPS AND THEIR ROLE IN DISASTER MANAGEMENT}

There have been several attempts to define the content of 3D environments. The content of 3D maps does not differ much from that of 2D maps, i.e., it should contain specific objects of interest in appropriate LOD with their semantics (of theme), symbols, colour composition, legend, and density of objects. As discussed above, the content of the 3D map is determined and designed after the definition of the objects and phenomena that will be included in the map. The content of a 3D map can be subdivided into three themes:

- Main content - large topographic or landscape objects such as relief bodies, roads, and buildings. Most 3D maps designed and presented by different companies contain only this content.

- Secondary content - basic information about small objects in the environment; for example, in 3D urban maps, objects represented by symbols, facilities, transport elements, information signs, trees, dam walls, and wells.

- Additional content - qualitative and quantitative information about objects, often created as a textual database, relating to each designed object or the map as a whole.

The main content is convenient for the visualisation of flood or fire situations because it provides basic information for all types of users. Secondary content, building upon main content, offers the potential for a higher level of decision making. Additional content includes the detailed information that allows various users (including researchers and analysts) to make more detailed analyses about crisis management situations. 
Many approaches have been followed to classify the functionalities that digital maps should offer. Heim (1998) defined three I-factors: immersion, interactivity and information Intensity (or Levels of Detail, LOD). MacEachren et al. (1999) added the I-factor of intelligence (about objects), which Wachowicz (2002) and Lammeren and Hogerwerf (2003) further extended. Zlatanova et al. (2010) suggested animation/video (a predefined walk-through), interaction (the ability to navigate, zoom, and manipulate), query (the ability to explore attributes of objects, e.g., the area of a house or apartment), feedback (the option to provide an opinion), and change (the option to edit the shape or position of a house) as additional attributes of functionality in 3D representations.

To investigate the need for 3D maps, their content, and their interaction, we performed several investigations in different countries with risk management or disaster management specialists (from municipalities) and citizens (including young people and children). Much attention was paid to the perception of 3D standards such as CityGML (www.citygml.org) and the LOD it offers. It was interesting to see that although $3 \mathrm{D}$ representations are attracting more attention, users are concerned about the availability and cost of data. The concept of LOD of CityGML (with which responders and the general public were not familiar) was seen as a very promising approach towards agreeing on standard abstractions and representations. Consensus was reached on what LOD is appropriate for many of the well-known, specific national maps. The general understanding was that simple LODs should be used for overview maps and for representation of spatial analysis (such as plume movement). Detailed LOD (LOD3 and LOD4) should be used when the view is from a street level and when indoor navigation is considered (Zlatanova et al., 2010).

Our research on young peoples' understanding of maps for disaster visualisation showed that they have some information about EW and CM without being taught in school.. Investigations with 10 - to 15-year-old students using topographic maps as a base material have shown that these students can work with maps effectively. Their only difficulty was the reading of contour lines on 2D maps. However, these students experienced no problems in explaining, using or manipulating 3D terrain models. Children like and easily become familiar with pictorial symbols representing different natural disasters. A symbol system was designed and tested with participants from Bulgaria, Czech Republic, Portugal, and Slovakia. The results showed that Portuguese children completely understood the content of Bulgarian topographic maps. This result indicates that the symbology of topographic maps could be an ideal basis for creating maps for early warning and disaster management (Bandrova et al., 2010).

This investigation on interaction with 3D maps clearly revealed that functionalities also need to be adapted to the user context. Interviewed specialists from municipalities were convinced that systems designed for citizens should not extend beyond receiving input from citizens. Citizens should not be granted rights to modify or delete information. Collecting information from citizens on a volunteer basis was also considered, but concerns were expressed about the validity and accuracy of this data. Such information has already been recorded and maintained but using the telephone connections, which allow a kind of quality control (Dilo and Zlatanova, 2011). Animations, navigations, and tools to explore objects via additional information from provided web links have been indicated as the most appropriate approach to learn more about events and disasters. However, a system that can manipulate all of the data to allow multi-view visualisations and even editing may be beneficial.

\section{REQUIREMENTS FOR 3D MAP COMPONENTS}

\subsection{Symbols}

Symbols play a critical role in risk and disaster management maps. Symbols are used to represent important (nontopographic) information, such as rescue units, shelters, dangerous locations, and the type of danger. Many authors and organisations have proposed standards for symbol systems to represent natural hazards and risk processes, but only for $2 \mathrm{D}$ maps. All of these systems are defined as national standards, but they are produced by different branches of science and practice and are often difficult for non-professional users to understand. In this respect, it is expected that 3D symbols will be better accepted by the general public. Three-dimensional symbols are able to convey more elaborate meaning. 3D symbols more accurately represent real objects and phenomena than 2D symbols. Therefore 3D symbols help the user in navigating through and orientation in the 3D model (Zlatanova and Bandrova, 1998).

Cartographic symbols should have clear and concise definitions to be easy to read and perceive. 3D symbols should be recognisable in 3D maps without a legend. An additional important characteristic is to be accurately located on a map to represent the real position of objects. Finally, 3D symbols should provide quality and quantity information about the object, phenomenon or process they represent.

The steps for symbol creation can be defined as follows:

- gathering information about an object (quality and quantity characteristics, images, textures);

- analysing information and collecting data about each object;

- designing symbols by applying computer graphics techniques;

- visualising symbols in the virtual or paper environment;

- providing additional tools querying information about an object.

Furthermore, symbols should cross cultural barriers as much as possible, relate to each other in a hierarchical or tiered structure, be based on common cartographic standards and perceptual research, and be visualised effectively in both low- and highresolution computer displays (Kostelnick et al., 2006).

\subsection{Colours}

Colour schemas can be defined using computer definitions of colours for screen presentation in the RGB colour schema. The United Nations ISDR Secretariat, which publishes many books and brochures to help teachers prepare for emergency situations, follows this approach. It produces emergency tables with different colours for many disasters. For example, 'green' is associated with no alarm, 'yellow' with vigilance, 'orange' with pre-alarm, and 'red' with alarm. These tables are widely used and should also be defined as a map standard in the visualisation of risks and disaster processes.

Colour definitions may help not only cartographers and mapmakers but also users who consume cartographic information via mobile phone, screen equipment, and paper versions of computer-generated ubiquitous 3D maps. 
Colours for visualisation of disasters are also proposed. The colours are highly saturated because the diagrams should be clearly visible on the map background. A second set of colours is defined for area symbols, which can be used background colours. Some examples are given below:

$$
\begin{aligned}
& \text { drought }-3 \mathrm{D} \text { point symbol } \quad R=255 \quad \mathrm{G}=250 \quad \mathrm{~B}=60 \\
& \text { earthquake }-3 \mathrm{D} \text { point symbol } \mathrm{R}=0 \quad \mathrm{G}=155 \quad \mathrm{~B}=80 \\
& \text { flood }-3 \mathrm{D} \text { point symbol } \quad \mathrm{R}=90 \quad \mathrm{G}=90 \quad \mathrm{~B}=160 \\
& \text {... } \\
& \text { drought }-3 \mathrm{D} \text { area symbol } \quad \mathrm{R}=255 \quad \mathrm{G}=250 \quad \mathrm{~B}=150 \\
& \text { earthquake }-3 \mathrm{D} \text { area symbol } \mathrm{R}=100 \quad \mathrm{G}=185 \quad \mathrm{~B}=95 \\
& \text { flood }-3 \mathrm{D} \text { area symbol } \quad \mathrm{R}=140 \quad \mathrm{G}=130 \quad \mathrm{~B}=180
\end{aligned}
$$

Standardisation in colouring for symbol systems and maps is a long-term process and might continue in different directions. Every colour system should be thoroughly tested and improved to become more clear and readable for users. Users' opinions on how they react to different colours in times of crisis may also be a useful line of investigation.

\subsection{Scale/LOD}

Scale/LOD is another important component for the development of maps for disaster management. Different countries maintain maps in different scales and resolutions. In many countries, the smallest scale is 1:200,000, and it is used on the national level for disaster management. Larger scales are used on a regional level, depending on the affected area. If a cartographic product is in $3 \mathrm{D}$, then measurements and design can be conducted using real dimensions, and visualisation can be performed on any suitable scale.

\subsection{Types of maps and generalisation}

In disaster management, five main types of cartographic products can be distinguished: risk maps, early warning maps, reference maps, assessment maps, and thematic maps. All of these products are used by headquarters, decision makers and on-field operations in Europe and worldwide. The term rapid mapping is often used to notate the quick recording of information on a map. Such mapping is performed immediately or as soon as possible after the disaster happens in case of humanitarian crises, natural disasters, and man-made emergency situations. A reference map produced in this way should be available within six hours after disaster strikes. The damage assessment maps should be available within 24 hours and updated daily, and the situation maps and forecasts of the evolution of situations should be ready within the first few days or weeks after a crisis (as recommended by GMES).

Indeed, appropriate databases and SDIs are required to prepare all of these types of maps. In many cases, generalisation on the basis of existing data or newly acquired data is required, but automatic generalisation is not recommended. Cartographers and specialists in crisis management have to decide which data in the database are appropriate for each case, each disaster management situation and each disaster. The so-called thematic generalisation is expected to be most suitable in this case. The level of generalisation should also be adapted to the aspects of the user context, i.e., activity, technology, user and situation (see Figure 2)

\section{CONCLUDING REMARKS AND DIRECTIONS FOR FUTURE WORK}

In this paper, we discussed the role of $3 \mathrm{D}$ maps in disaster management. We argue that $3 \mathrm{D}$ maps have the potential to improve the disaster management process. Three-dimensional maps can resolve many perception problems and provide more clearly presented information. Our user interviews have confirmed that young people prefer 3D information. However, the preparation of 3D maps involves much more labour in both the design of appropriate 3D map content and the development of appropriate functionality for 3D map interactions. The 3D map should be flexible, adaptive and prepared with respect to the context of the user, the type of disaster, and the phase of disaster management. The research on these topics will require the integrated efforts of researchers from many different disciplines, including cartography, knowledge engineering, cognitive science, computer graphics, and human-machine interaction.

An important task of cartography educators is to prepare the general public to read and understand geographical data. This preparation should begin in schools. Currently, materials for educating children exist in many countries, but they have limited distribution. A number of pilot projects are devoted to educating children, but the efforts are still insufficient.

The major challenge for disaster management is standardisation. All efforts should be directed towards establishing an international standardisation process. This process could begin by using data standards for map components, such as data classification, map content, map symbology or presentation, and data usability. The processes related to map design are also matters of standardisation. Many international organisations have initiated activities towards achieving this goal.

The International Cartographic Association (ICA) is taking a leading role in preparing guides on map-making for early warning, risk and disaster management, and emergency needs. The ICA follows resolutions and agreements from the World Summit on Sustainable Development (www.worldsummit2002.org) but mainly from the United Nation Hyogo Framework (www.unisdr.org). The primary activity of the ICA is the establishment of a working group in this field. The activities of this group focus on the organisation of various worldwide meetings and seminars as well as the propagation of cartography and GI technologies in risk and crises management. Similar initiatives are ongoing in other international organisations, such as ISPRS, IUGG, FIG, and JBGIS (Altan et al., 2010).

It is clear that different international organisations should cooperate to define mapping standards for risk and disaster management. Some very successful steps in this direction have been taken by United Nations (UN) ISDR Secretariat and, recently, by the IRDR initiative (Integrated Research on Disaster Risk). OGC has also recognised the need for mapping standards and has established a special domain working group on disaster management.

\section{REFERENCES}

Altan, O., R. Backhaus, P. Boccardo and S. Zlatanova, 2010, Geoinformation for Disaster and Risk Management: Examples and Best Practices, JB GIS and UNOOSA, Copenhagen, Denmark, 142 p. 
Bandrova, T. and M. Konecny, 2006, Mapping of Nature Risks and Disasters for Educational Purposes. 127-134. In: Conference Collection of Papers, Volume II, VIth International Scientific Conference, Modern Management of Mine Producing, SGEM 2006. 12-16 June 2006. Bulgaria. $514 \mathrm{pp}$

Bandrova, T., M. Konecny and M. Rusnakova, 2010, Research of Students' Cartographical Knowledge in Early Warning and Crisis Management. In Geographic Information and Cartography for Risk and Crisis Management. LNGC. Springer, Heidelberg, 2010, pp. 361378 .

Barrie, A., 2011, FoxNews, Exclusive: Saab Unveils Amazing 'Magic Maps' for Military - How long before it's used against citizens? Available at: http://www.foxnews.com/scitech/2011/ (last accessed March 2012).

Bell, R. and T. Glade, 2004, Multi-hazard analysis in natural risk assessment. In: Brebbia C. A., (eds), Risk Analysis IV, Southampton, Boston, WIT Press, p. 196-206.

Charvat K., P. Kubicek, V. Talhover, M. Konecny and J. Jezek, 2008, Spatial Data Infrastructure And Geovisualisation In Emergency Management. Resilience of Cities to Terrorist and other Threats: Learning from 9/11 and further Research Issues. Springer - Verlag, Dordrecht :, 2008. 32 s.

Cooley, M.J, L. R. Davis, K. A. Fishburn, H. Lestinsky, and L. R. Moore, 2011, US Topo Product Standard, USGS, 30. Nov. 2011, 24p., available at: http://mngeoepc.blogspot.com/2011_11_01_archive.html (last accessed January 2012)

Dilo, A. and S. Zlatanova, 2011, A data model for operational and situational information in emergency response: The Dutch case, In: Applied Geomatics (2011) 3:207-218

Durden, T., 2011, GoogleEarth Based 3D Map of real-time radioactivity distribution in Japan; Projected Global Radioactivity Dispersion, available at: http://www.zerohedge.com/article/googleearthbased-3d-map-real-time-radioactivity-distribution-japan (last accessed January 2012)

Goodchild, M.F. and J.A. Glennon, 2010, Crowdsourcing geographic information for disaster response: a research frontier. International Journal of Digital Earth, 3(3), 231-241.

Heim, M., 1998, Virtual Realism. New York, New York: Oxford. pp. $162-167$

ISDR, World Conference on Disaster Reduction, Action 20052015:Building the Resilience of Nations and Communities to Disasters; 18-22 January 2005, Kobe, Hyogo, Japan, Available at: http://www.unisdr.org/2005/wcdr/intergover/official-doc/L-

docs/Hyogo-framework-for-action-english.pdf (last accessed January 2012)

Konecny, M., P. Kubicek, Z. Stachon and C. Sasinka, 2011a: The Usability of Selected Base Maps for Crises Management - Users' Perspectives. Applied Geomatics 3, pp. 189-198

Konecny, M., E. Mulickova, P. Kubicek and J. Li, 2011 b. Geoinformation Support for Flood Management in China and the Czech Republic, Foreword. Vyd. 1. Brno : Masarykova univerzita, 2011. 119 p.

Kostelnick, J., J. Dobson, S. Egbert and M. Dunbar, 2006, A Cartographic Study of IMSMA Symbology: Reviewing Its Value for operations, $2 \mathrm{p}, \quad$ available at: http://www.gichd.ch/fileadmin/pdf/IMSMA/summer_workshop/Kosteln ick_et_al.pdf (last accessed January 2012).

Kozel, J. and R. Stampach, 2010, Practical Experience with a Contextual Map Service. Geographic Information and Cartography for Risk and Crisis Management - Towards Better Solutions. Lecture Notes in Geoinformation and Cartography, 1st Edition. Heidelberg Dordrecht London New York : Springer-Verlag, pp. 305-316.

Lammeren, R. van and T. Hoogerwerf, 2003, GeoVirtual Reality and participatory planning, Virtual Landscape position paper, Alterra, Wageningen University, Centrum voor Geo-Informatie, CGI Report 2003-07 ISSN 1568-1874

MacEachren, A.M., R. Edsall, D. Haug, R. Baxter, G. Otto, R. Masters, S. Fuhrman and L. Qian, 1999, Exploring the potential of virtual environments for geographic visualization, available http://www.geovista.psu.edu/publications/aag99vr/fullpaper.htm (last accessed January 2012)

Neuvel, J. and S. Zlatanova, 2006, The void between risk prevention and crisis response, In: Fendel and Rumor (Eds); Proceedings of UDMS'06 Aalborg, Denmark May 15-17, 2006, TU Delft, 2006, pp. 6.1-6.14

Parasuraman, S. and P.V. Unnikrishnan, 2004, Disaster response in India: An Overview, available at: http://www.punjabilok.com/india_disaster_rep/introduction/overview.ht m (last accessed January, 2012)

Rajabifard, A., 2007, Towards a Spatially Enabled Society (Ed.), The University of Melbourne. ISBN: 978-0-7325-1620-8, pp 400.

Reznik, T., B. Horakova and D. Janiurek, 2011, Emergency Support System: Actionable Real-time Intelligence with Fusion Capabilities and Cartographic Displays. Journal of Advances in Military Technology, Brno: Univerzita obrany, 6/2011, 2, pages 83-97. ISSN 1802-2308.

Snoeren, G., S. Zlatanova, J. Crompvoets and H. Scholten, 2007, Spatial Data Infrastructure for emergency management: the view of the users. Proceedings of the 3rd International symposium on Gi4DM, 2225 May, Toronto, Canada, CDROM, 12 p.

Stanek, K., M. Konecny, and L. Friedmannova, 2007. An adaptive cartographic visualization for support of the crisis management. In: XXIII International Cartographic Conference. Moscow: Roskartographija, on CD-ROM, 9 pages,

Stringfield, W,H 1996, Emergency planning and management, Rockville: Government Institutes

Wachowicz, M., J. Bulens, F. Rip, H. Kramer, R. van Lammeren and A. Ligtenberg, 2002, Wageningen UR Centre for Geo-Information, 5th AGILE Conference on Geographic Information Science, Palma, Balearic Islands, Spain, April 25th- 27th 2002

Worm, Van den J., 2006, Cartographic Visualization Aspects of the web-based Dutch National Risk Map, 17p., available at: http://gis.esri.com/library/userconf/proc03/p0802.pdf (last accessed January 2012), 2006.

Zlatanova, S. and T. Bandrova, 1998, User requirements for the third dimensionality, In: E-mail seminar of Cartography 1998: Maps of the future, Vol. 1, Sofia, Bulgaria, pp. 61-72

Zlatanova, S., L. Itard, M. S. Kibria and M. van Dorst, 2010, A user requirements study of digital $3 \mathrm{D}$ models for urban renewal, In: Open House International, Volume 35, 3, pp. 37-46

Zlatanova, S., 2008, SII for Emergency Response: the 3D Challenges, In: Chen, Jiang and Nayak (Eds,), Proceedings of the XXI ISPRS Congress, Part B4-TYC IV, July 2008, Beijing, pp. 1631-1637

Zlatanova, S., 2010, Formal modelling of tasks to support search of geo-information in emergency response, In: Das (Eds.), International symposium climate change and disaster management, Noida, India: GIS Development Pvt. Ltd., pp. 26-36 